\title{
KARAKTERISTIK MORFOLOGI JENIS TANAMAN HIAS PEKARANGAN RUMAH DI KELURAHAN PLAJU ULU KOTA PALEMBANG
}

\author{
Pebriana Kartika Sari ${ }^{*}$, Dewi Rosanti ${ }^{2}$, Yunita Panca Putri ${ }^{3}$ \\ ${ }^{1,2,3}$ Program Studi Biologi, Fakultas Sains dan Teknologi \\ Universitas PGRI Palembang \\ *e-mail: febrianakartika71@gmail.com
}

\begin{abstract}
Research on the morphological characteristics of ornamental plant species in the home garden in Plaju Ulu Village, Palembang City, has been carried out from March to June 2021, aiming to determine the morphological characteristics of ornamental plants in Plaju Ulu Village, Palembang City. This study uses a descriptive survey method by exploring the village area as many as 3 RT. Observations were made by looking directly at the ornamental plants found and then recorded, photographed and then described morphologically. The results obtained 2 classes, 21 orders, 24 families, 36 genera and 36 species of ornamental plants. The species obtained had roots (Radix) with a fibrous root system (Radix adventicia) and tap (Radix primaria). The stem has a wet stem structure and woody shrubs and pseudo stems that are modified into rhizomes. Leaves are heartshaped, shield, oblong, sword, lanceolate, elongated, triangular, ovoid, round and asymmetrical. Flowers have a single flower structure and compound flowers, cobs, bunches, umbrellas, grains, pots and cups. The fruit structure is a single true fruit dry, box fruit, buni fruit, bracket fruit, kendaga fruit and fleshy pseudo fruit. Accessory organs consist of tubers and spines.
\end{abstract}

Keywords: Ornamental plants, Morphological characteristics.

\begin{abstract}
ABSTRAK
Penelitian tentang karakteristik morfologi jenis tanaman hias pekarangan rumah di Kelurahan Plaju Ulu Kota Palembang, telah dilaksanakan pada bulan Maret sampai dengan Juni 2021, bertujuan untuk mengetahui karakteristik morfologi tanaman hias di Kelurahan Plaju Ulu Kota Palembang. Penelitian ini menggunakan metode survey deskriptif dengan menjelajahi wilayah kelurahan sebanyak 3 RT. Pengamatan dilakukan dengan melihat langsung tanaman hias yang ditemukan kemudian dicatat, difoto lalu dideskripsikan secara morfologi. Hasil penelitian diperoleh 2 class, 21 ordo, 24 familia, 36 genus dan 36 spesies tanaman hias. Spesies yang diperoleh memiliki akar (Radix) dengan sistem perakaran serabut (Radix adventicia) dan tunggang (Radix primaria). Batang berstruktur batang basah dan berkayu jenis semak serta batang semu yang termodifikasi menjadi rimpang. Daun berbentuk jantung, perisai, jorong, pedang, lanset, memanjang, segitiga, bulat telur, bulat dan asimetris. Bunga berstruktur bunga tunggal dan bunga majemuk, tongkol, tandan, payung, bulir, periuk dan cawan. Buah berstruktur buah sejati tunggal kering, buah kotak, buah buni, buah kurung, buah kendaga dan buah semu berdaging. Organ asesoris terdiri dari umbi dan duri.
\end{abstract}

Kata Kunci: Tanaman hias, Karakteristik morfologi. 


\section{PENDAHULUAN}

Kota Palembang yaitu salah satu kota besar di Indonesia yang dimana memiliki padat penduduk. Semakin tinggi jumlah penduduk maka akan diikuti dengan tingginya aktivitas dan pembangunan di dalam kota tersebut. Secara umum masyarakat Kota Palembang banyak memanfaatkan lahan di pekarangan rumahnya dengan melakukan penanaman tanaman hias. Semenjak masa pandemi ini, kebanyakan masyarakat hobi merawat tanaman hias menjadi populer dan diminati oleh banyak orang (Rosanti dan Wiranata, 2018).

Kejadian seperti ini salah satunya dipicu oleh adanya pembatasan aktivitas di luar rumah, sehingga banyak masyarakat memanfaatin waktu luangnya di rumah selama pandemi dan ini membuat banyak orang mengeksplorasi hobi baru yaitu dengan merawat tanaman hias dan menjadikannya peluang bisnis baru di tengah keterbatasan bisnis akibat kondisi pandemi (Balai Penelitian Tanaman Hias, 2020).

Secara bahasa morfologi berasal dari kata Morphologi (Morphe: bentuk, logos: ilmu) berarti ilmu yang mempelajari bentuk-bentuk luar dari tumbuhan, khususnya tumbuhan berbiji mengenai organ-organ tubuhnya dengan segala variasinya (Rosanti, 2013). Karakteristik morfologi tumbuhan yang bisa diamati antara lain bagian-bagian daun dan bentuknya, tipe daun, tata letak daun, bentuk batang, arah tumbuh batang, percabangan batang, sistem perakaran serta bentuk akar (Widya et.al., 2019).

Pekarangan dapat diartikan sebagai sebidang tanah atau sepetak tanah yang berada di sekitar rumah yang umumnya berada di bagian belakang, samping atau depan bangunan rumah. Pekarangan bukan hanya untuk menciptakan keindahan dan kesejukan saja, tetapi lebih dari pada itu adalah guna meningkatkan perekonomian keluarga masing-masing. Jenis-jenis tanaman yang bisa ditanam di pekarangan rumah masing-masing adalah jenis sayursayuran, buah-buahan, obat-obatan, tanaman hias, dan lain sebagainya yang kesemuanya itu dapat menunjang kebutuhan sehari-hari dan selebihnya bisa dijual (Dwiratna et.al., 2016).

Tanaman hias merupakan tanaman yang memiliki bentuk unik dan khas yang berfungsi sebagai dekorasi ataupun hiasan baik dalam ruangan maupun luar ruangan. Dahulu tanaman hias merupakan tanaman yang hanya berbunga saja, namun seiring perkembangan zaman tanaman hias didefinisikan sebagai tanaman yang memiliki nilai indah baik daun, bunga, batang, buah, ranting, aroma maupun akar yang bernilai artistik atau seni. Tanaman hias sudah menjadi tren di zaman sekarang, karena selain mempercantik tempat juga memberikan udara segar di sekitarnya dan juga dapat bermanfaat dalam sumber pewarna alami (Sangadji et.al., 2017).

Berdasarkan penelitian Palupi (2018), bahwa jenis tanaman pekarangan Gn. Dubbs Balikpapan diperoleh 9 spesies serta 9 famili yang berhabitus (pohon, perdu, semak, terna, dan herba) diantaranya Allamanda cathartica (famili Apocynaceae), Europhibia milii (famili Euphorbiaceae),Caesalpinia pulcherrima (famili Fabaceae), Orthosiphon stamineus (famili Laminaceae), Hibiscus rosa-sinensis (famili Malvaceae), Muntingia calabura (famili Elaeocarpaceae), Mirabilis jalapa dan Bougainvillea sp (famili Nyctaginaceae), Ixora sp (famili Rubiaceae). Sedangkan ciri morfologi polen tanaman pekarangan ialah tipe aperture (inaperture, periporalate, syncolpalate, monoporalate, diporalae, tricolpalate dan stephanocolpate), bentuk ornamentasi (reticulate, baculate, striate, verrucate, regulate dan scabrate). 
Berdasarkan uraian diatas dilakukan penelitian tentang morfologi seperti akar, batang, daun, bunga, buah dan organ asesoris dari berbagai jenis tanaman hias di pekarangan rumah.

\section{BAHAN DAN METODE}

Penelitian ini telah dilaksanakan di Kelurahan Plaju Ulu Kota Palembang. Waktu penelitian dari bulan Maret sampai Juni 2021.

Adapun alat yang digunakan dalam penelitian ini adalah Alat tulis, buku, panduan dari Rosanti (2013) dan Tjitrosoepomo (2011), yaitu "Morfologi Tumbuhan" dan kamera. Sedangkan bahan yang digunakan adalah berbagai macam tanaman hias di Kelurahan Plaju Ulu Kota Palembang.
Metode penelitian ini dilakukan dengan penjelajahan di Kelurahan Plaju Ulu Kecamatan Plaju Kota Palembang. Pengambilan sampel dengan cara observasi langsung ke Kelurahan Plaju Ulu. Metode yang digunakan dalam penelitian ini adalah metode survey deskriptif yaitu penjelajahan dimulai dari RT 04, RT 06 dan RT 17. Survey dilakukan dengan melihat langsung tanaman hias yang terdapat di Kelurahan Plaju Ulu dan melakukan wawancara dengan masyarakat setempat. Data yang diperoleh dari pengamatan secara langsung pada setiap tanaman yang ada di pekarangan rumah tersebut dengan melihat morfologi pada bagian tanaman yaitu akar, batang, daun, bunga, buah dan organ asesoris.

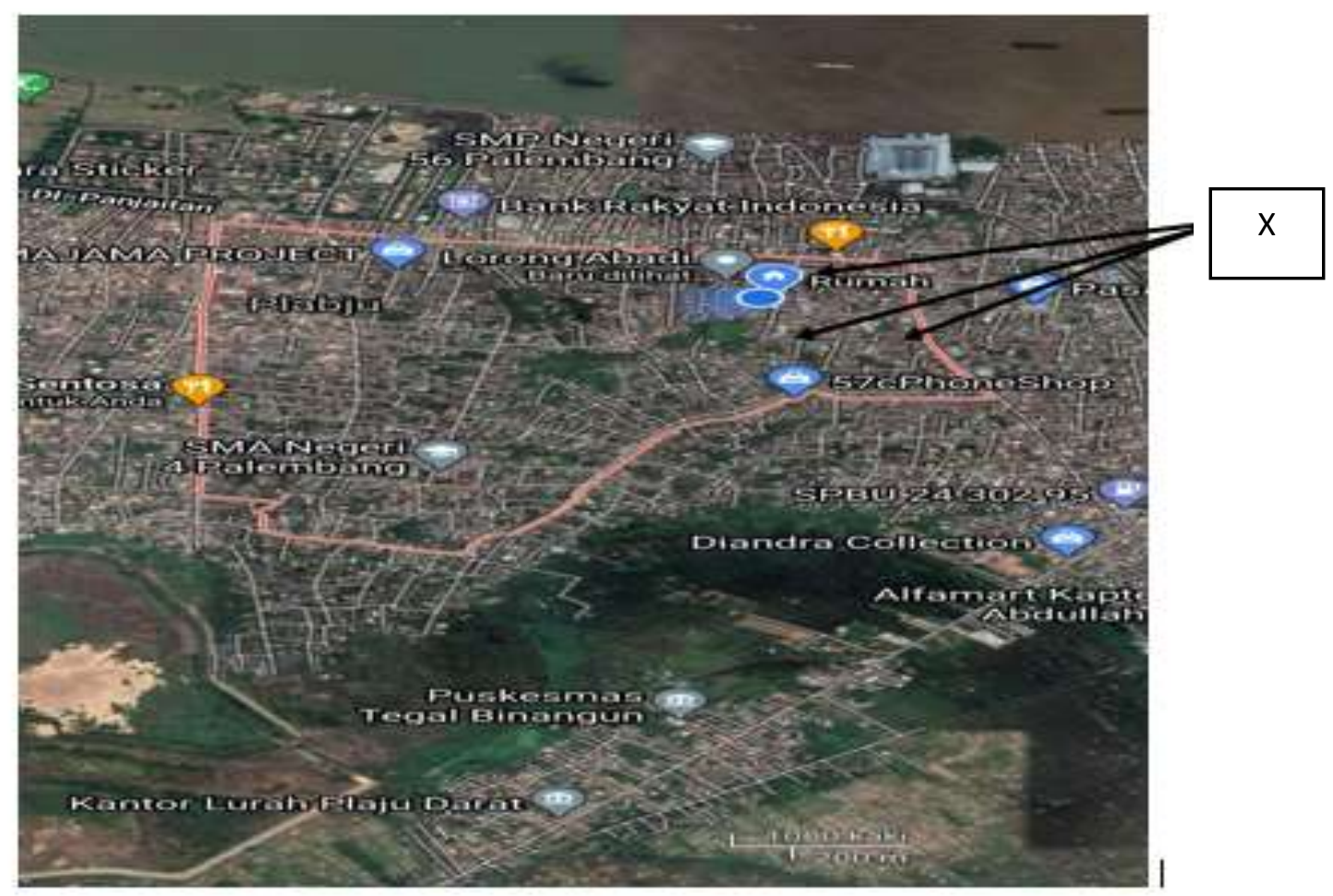

Gambar. Lokasi Penelitian (Sumber: Google Maps, 2021)

Keterangan: $\mathrm{X}=$ Lokasi Penelitian 


\section{HASIL DAN PEMBAHASAN}

\begin{abstract}
Pada penelitian di Kelurahan Plaju Ulu ini terdapat 3 RT yang dijelajahi secara langsung dimana tanaman hias yang ditemukan hampir disetiap rumah memiliki tanaman hias dengan berbagai jenis namun jumlahnya yang tidak banyak dan berbeda-beda tanaman hias di Kelurahan Plaju Ulu merupakan tanaman yang disengaja di tanam untuk keindahan halaman rumah, ada yang menanamnya langsung di tanah, ada juga yang menggunakan pot dan disusun rapi di depan maupun di samping rumah.
\end{abstract}

Tipe morfologi akar yang ditemukan pada tanaman hias adalah akar serabut dan akar tunggang. Pada akar serabut (Radix adventicia) merupakan akar yang dalam lembaga perkembangannya mati atau kemudian disusul oleh sejumlah akar yang dimana akarnya ini kurang lebih sama besar dan semuanya keluar dari pangkal batang. Akar ini bukan berasal dari calon akar yang asli melainkan calon akar liar. Pada akar tunggang (Radix primaria) ini jika akar lembaga tumbuh terus menjadi akar pokok yang bercabang-cabang menjadi akar-akar yang lebih kecil (Tjitrosoepomo, 2011).

Tipe morfologi batang tanaman hias yang ditemukan batang berkayu (lignosus) adalah batang yang disusun oleh jaringan lignin. Karena batang bersifat keras dan kuat. Tipe morfologi daun dari tanaman hias yang ditemukan berbangun bulat telur (pangkal daunnya yang tidak berlekuk), memanjang (daun yang memiliki perbandingan lebar dan panjang daun berkisar antara $2 \frac{1}{2}-3: 1$ ), lanset (daun yang memiliki perbandingan lebar dan panjang daun berkisar antara 3$5: 1$ ), segitiga (bangun seperti segi tiga sama kaki), perisai (daun yang biasanya bangun bulat, mempunyai tangkai daun yang tidak tertanam pada pangkal daun, melainkan pada bagian tengah helaian daun), jorong (bila perbandingan panjang dan lebar helaian daun melalui garis bantu berkisar antara 1,5:1 sampai 2 : 1), jantung (bila pangkal daunnya bertoreh atau berlekuk), pedang (helaian daun yang tebal dan kaku, dengan berbentuk panjang) dan bulat (bila garis sketsa menggambarkan perbandingan panjang dengan lebar $1: 1$ ).

Tipe morfologi bunga yang ditemukan kebanyakan bertipe bunga majemuk (suatu bunga majemuk yang dapat dibedakan dari cabang yang mendukung sejumlah bunga di ketiaknya ) dan bunga tunggal (satu tangkai mendukung satu bunga), bunga yang terdapat di ketiak daun (Flos axillaris) bunga pada ujung batang (Flos terminalis) (Tjitrosoepomo, 2013). Buah berstruktur buah sejati tunggal kering, buah kotak, buah buni, buah kurung, buah kendaga, buah semu berdaging dan buah.

Dari hasil penelitian di Kelurahan Plaju Ulu Kecamatan Plaju Kota Palembang tentang tanaman hias, berasal dari 1 divisio yaitu Spermatophyta, terdapat 2 class yaitu Monocotyledoneae dan Dicotyledoneae , 21 ordo, 24 familia, 36 genus dan 36 spesies.

Class monocotyledoneae diperoleh 3 ordo, 3 familia, 9 genus dan 9 spesies (Epipremnum aureum, Caladium tricolor, Aglaonema crispum, Dieffenbachia bowmanii, Sansevieria trifasciata, Monstera adansonii, Cordyline fruticosa, Arachis flos-aeris) dan pada class Dicotyledoneae diperoleh 18 ordo, 21 familia, 27 genus dan 27 spesies (Syzygium oleana, Excoecaria cochinchinensis, Oxalis triangularis, Rosa sinensis, Hibiscus rosa-sinensis, Nothopanax scutellarium, Begonia rex, Coleus scutellariodes, Mirabilis jalapa, Ruellia tuberosa, Jasminum 
sambac, Catharanthus roseus, Adenium obesum, Impatiens balsamina, Chrysanthemum pompoms, Ficus pumila, Mussaenda frondosa, Saraca asoca, Isotoma lingiflora, Cananga odorata, Bougainvillea spectabilis, Allamanda cathartica, Celosia argentea, Euphorbia mili, Codiaeum variegatum L, Lavandula angustifolia mill, Zinnia elegans jaqc ). Secara lengkap spesies tanaman hias yang ditemukan di Kelurahan Plaju Ulu disajikan pada Tabel di bawah ini :

Tabel. Spesies Tanaman Hias di Kelurahan Plaju Ulu Kota Palembang

\begin{tabular}{|c|c|c|c|c|c|c|}
\hline No & Class & Ordo & Familia & Genus & Spesies & Nama Lokal \\
\hline 1 & Monocotyledoneae & Arecales & Araceae & Epipremnum & Epipremnum aureum & Sirih gading \\
\hline 2 & & & & Caladium & Caladium tricolor & Keladi tricolor \\
\hline 3 & & & & Aglaonema & $\begin{array}{l}\text { Aglaonema commutatum } \\
\text { Schott }\end{array}$ & Aglonema lipstik \\
\hline 4 & & & & Dieffenbachia & Dieffenbachia bowmanii & Daun bahagia \\
\hline 5 & & & & Anthurium & Anthurium palmatum & Gelombang cinta \\
\hline 6 & & & & Monstera & Monstera adansonii & Janda bolong \\
\hline 7 & & Liliales & Liliaceae & Sansevieria & Sansevieria trifasciata & Lidah mertua \\
\hline 8 & & & & Cordyline & Cordyline fruticosa & Andong \\
\hline 9 & & Orchidales & Orchidaceae & Arachnis & Arachnis flos-aeris & $\begin{array}{l}\text { Anggrek } \\
\text { kalajengking }\end{array}$ \\
\hline 10 & Dicotyledoneae & Myrtales & Myrtaceae & Syzygium & Syzygium oleana & Pucuk merah \\
\hline 11 & & & & Excoecaria & Excoecaria cochinchinensis & Sambang darah \\
\hline 12 & & Oxalidales & Oxalidaceae & Oxalis & Oxalis triangularis & $\begin{array}{l}\text { Bunga kupu- } \\
\text { kupu }\end{array}$ \\
\hline 13 & & Malvales & Malvaceae & Hibiscus & Hibiscus rosa-sinensis & Kembang sepatu \\
\hline 14 & & Apiales & Araliaceae & Nothopanax & Nothopanax scutellarium & Mangkokan \\
\hline 15 & & Violales & Begoniaceae & Begonia & Begonia rex & Begonia \\
\hline 16 & & Solanales & Lamiaceae & Coleus & Coleus scutellariodes & Ati-ati \\
\hline 17 & & Caryophyllales & Nyctaginaceae & Mirabilis & Mirabilis jalapa & Pukul empat \\
\hline 18 & & & & Bougainvillea & Bougainvillea spectabilis & Kembang kertas \\
\hline 19 & & & Amaranthaceae & Celosia & Celosia argentea & Jengger ayam \\
\hline 20. & & Rosales & Rosaceae & Rosa & Rosa sinensis & Mawar \\
\hline 21. & & Urticales & Moraceae & Ficus & Ficus pumila & Dolar \\
\hline 22. & & Gentianales & Apocynaceae & Catharanthus & Catharanthus roseus & Tapak dara \\
\hline 23. & & & & Adenium & Adenium obesum & Kamboja jepang \\
\hline 24. & & & & Allamanda & Allamanda cathartica & Alamanda \\
\hline 25. & & & Rubiaceae & Mussaenda & Mussaenda frondosa & Nusa indah \\
\hline 26 & & Asterales & Asteraceae & Chrysanthemum & Chrysanthemum pompoms & Krisan pompom \\
\hline 27 & & & & Zinnia & Zinnia elegans & Zinnia anggun \\
\hline 28 & & & Campanulaceae & Isotoma & Isotoma lingiflora & Katarak \\
\hline 29 & & Geraniales & Balsaminaceae & Impatiens & Impatiens balsamina & Pacar air \\
\hline 30 & & Magnoliales & Annonaceae & Cananga & Cananga odorata & Kenanga \\
\hline 31 & & Scrophulariales & Acanthaceae & Ruellia & Ruellia tuberosa & $\begin{array}{l}\text { Kencana } \\
\text { ungu }\end{array}$ \\
\hline 32 & & Lamiales & Lamiaceae & Lavandula & Lavandula angustifolia mill & Lavender \\
\hline 33 & & Rubiales & Rubiaceae & Ixora & Ixora grandiflora & Asoka \\
\hline 34 & & Oleales & Oleaceae & Jasminum & Jasminum sambac & Melati putih \\
\hline 35 & & Euphorbiales & Euphorbiaceae & Euphorbia & Euphorbia mili & Ekorbia \\
\hline 36 & & & & Codiaeum & Codiaeum variegatum & Daun puring \\
\hline
\end{tabular}


Pada Tabel di atas, ordo yang terbanyak yaitu ordo Arecales, ordo Gentianales dan ordo Asterales. Ordo Arecales terdapat pada tanaman sirih gading, keladi tricolor, aglonema lipstik, daun bahagia, gelombang cinta dan janda bolong, ordo Gentianales terdapat pada tanaman tapak dara, alamanda, nusa indah dan kamboja jepang dan ordo Asterales terdapat pada tanaman krisan pompom, zinnia anggun dan katarak. Pada familia yang terbanyak yaitu familia Araceae dan Apocynaceae pada Araceae terdapat pada tanaman sirih gading, keladi tricolor, aglonema, daun bahagia, gelombang cinta dan janda bolong sedangkan pada familia Apocynaceae terdapat pada tapak dara, alamanda dan kamboja jepang.

Morfologi tumbuhan yang diamati meliputi akar (Radix) dengan sistem perakaran serabut (Radix adventicia) dan tunggang (Radix primaria). Morfologi batang (Caulis) meliputi struktur, jenis, bentuk dan permukaan batang (batang semu, batang basah, dan batang berkayu). Morfologi daun (Folium) meliputi bangun daun (Circumscriptio) bertipe jantung (Cordatus), perisai (Peltatus), jorong (Ovalis), memanjang (Oblangus), pedang (Ensiformis), lanset (Lanceolatus), segitiga (Triangularis), bulat telur (Ovatus), bulat (Orbicularis), asimetris.

Menurut Tjitrosoepomo (2013), emergensia (emergentia), yaitu alat-alat tambahan yang tidak hanya tersusun atas bagian-bagian kulit luar, akan tetapi bagian yang lebih dalam dari pada kulit luar ikut pula mengambil bagian dalam permukaannya. Emergensia dapat berupa rambut-rambut gatal atau perangsang (stimulus), yaitu rambut-rambut yang ujungnya mudah patah, dan jika sudah patah ujungnya menjadi alat semacam jarum penyuntik yang tajam, mudah menusuk kulit, dan melalui liang pada ujungnya tadi ke dalam kulit dimasukkan zat-zat yang kepada kulit memberikan rasa gatal dan panas. Selain rambut gatal emergensia dapat pula berupa duri tempel (aculeus), duri yang mudah ditanggalkan dari alat yang mendukungnya, mislanya pada mawar (Rosa sp.).

Keragaman tumbuhan memiliki fungsi yaitu untuk menciptakan pelestarian lingkungan hidup pada pekarangan, sehingga pekarangan berperan penting dalam pemenuhan kebutuhan sehari-hari, meningkatkan pendapatan penduduk, memberikan keindahan, kenyaman dan sebagai penyaring udara (Andriansyah et al., 2015).

\section{KESIMPULAN}

Karakteristik morfologi tanaman hias yang ditemukan di Kelurahan Plaju Ulu adalah :

1. Akar terdiri dari akar tunggang (Radix primaria) dan akar serabut (Radix adventicia).

2. Batang berstruktur batang basah dan berkayu jenis semak serta batang semu yang termodifikasi menjadi rimpang.

3. Daun berbentuk jantung, perisai, jorong, pedang, lanset, memanjang, segitiga, bulat telur, bulat dan asimetris.

4. Bunga berstruktur bunga tunggal dan bunga majemuk, tongkol, tandan, payung, bulir, periuk dan cawan.

5. Buah berstruktur buah sejati tunggal kering, buah kotak, buah buni, buah kurung, buah kendaga dan buah semu berdaging.

6. Organ asesoris terdiri dari umbi dan duri.

\section{DAFTAR PUSTAKA}

Andriansyah, S.N., L. Irwan. dan L. Riza. 2015. Keanekaragaman Jenis Tanaman Pekarangan di Desa Antibar Kecamatan Mempawah 
Timur Kabupaten Mempawah. Jurnal Protobiont. Vol. 4 No. 1: 226-235.

Balai Penelitian Tanaman Hias. 2020. Tanaman Hias Ditengah Pandemi Covid-19. http://balithi.litbang.pertanian.go .id/varietas-unggul.

Dwiratna, N.P. S., A. Widyasanti., dan D.M. Rahmah. 2016. Pemanfaatan Lahan Pekarangan Dengan Menerapkan Konsep Kawasan Rumah Pangan Lestari. Jurnal Aplikasi Ipteks untuk Masyarakat. Vol. 5 No. 1: 19-22.

Palupi, E., Syafrizal., Hariani, N. 2018. Studi Morfologi Polen Tanaman Pekarangan di Perumahan Gn. Dubbs Balikpapan. Jurnal Bioprospek. Vol. 13 No. 2: 1621.

Rosanti, D. 2013. Morfologi Tumbuhan. Jakarta: Erlangga.

Rosanti, D. Dan R.R. Wiranata. 2018. Morfologi Orchidaceae di Kebun Raya Liwa Kabupaten Lampung Barat Provinsi Lampung. Jurnal Ilmiah Matematika dan Ilmu Pengetahuan Alam. Vol. 15. No. 2: 84-89.

Sangadji I., M. Rijal dan Y. Astri Y. 2017. Kandungan Antosianin di Dalam Mahkota Bunga Beberapa Tanaman Hias. Jurnal Biology Science \& Education. Vol. 6 No. 2: 119.

Tjitrosoepomo, G. 2011. Morfologi Tumbuhan. Yogjakarta: Gajah Mada University Press.
Widya, M., D.J. Ria dan H. Fitriani. 2019. Karakteristik Morfologi dan Anatomi Jahe (Zingiber of ficinale) Berdasarkan Perbedaan Ketinggian Tempat. Jurnal Pendidikan Biologi dan Sains (BIOEDUSAINS). Vol. 2 No. 2: 60-69. 